Review

\title{
Fundamental Properties of Packing Materials for Liquid Chromatography
}

\author{
Toshihiko Hanai $(\mathbb{D}$
}

Health Research Foundation, Kyoto 606-0805, Japan; thanai@kf7.so-net.ne.jp; Tel.: +81-75-702-1141

Received: 14 November 2018; Accepted: 25 December 2018; Published: 5 January 2019

\begin{abstract}
The high performance of chemically-modified silica gel packing materials is based on the utilization of pure silica gels. Earlier silica gels used to be made from inorganic silica; however, nowadays, silica gels are made from organic silanes. The surface smoothness and lack of trace metals of new silica gels permits easy surface modifications (chemical reactions) and improves the reproducibility and stability. Sharpening peak symmetry is based on developing better surface modification methods (silylation). Typical examples can be found in the chromatography of amitriptyline for silanol testing and that of quinizarin for trace metal testing. These test compounds were selected and demonstrated sensitive results in the measurement of trace amounts of either silanol or trace metals. Here, we demonstrate the three-dimensional model chemical structures of bonded-phase silica gels with surface electron density for easy understanding of the molecular interaction sites with analytes. Furthermore, a quantitative explanation of hydrophilic and hydrophobic liquid chromatographies was provided. The synthesis methods of superficially porous silica gels and their modified products were introduced.
\end{abstract}

Keywords: chemically bonded silica gels; selectivity of packing materials; retention mechanisms; in silico; hydrophobic interaction; hydrophilic interaction; Lewis acid-base interaction; ion-ion interaction; superficially porous silica gels

\section{Introduction}

This aim of the review is to explain the properties of the bonded phases. First, definition in liquid chromatography was described using in silico analysis. We then visualized the electron localization of the ligands and the selective molecular interaction that is used to teach organic synthesis chemistry and charge transfer complexes. Then, new developments in bonded-phases were summarized especially for ionic liquid phases. In addition, the historical background, synthesis methods, and specificities of superficially porous silica gels were described.

Since the last review [1], the inertness and chemical stability of current bonded-phase silica gels have been improved by the development of chemical surface modification methods for silica gels. The theoretical analysis of packing materials based on the van Deemter equation has been applied to determine the performance of recently developed superficially porous (core-shell and fused-core) particles [2-12]. The physical performance of columns is well discussed; however, the chemical part of retention mechanisms of packing materials was not described quantitatively. The retention of analytes on, or in, a stationary phase depends on the physicochemical interaction between the analytes and the stationary-phase material. When a strong solvent, in which the analyte readily dissolves, is used for elution, the analyte is eluted very quickly from the column. The forces holding an analyte on the stationary phase are similar to those responsible for its dissolution in the solvent. Eight solubility factors are recognized: van der Waals force (a combination of van der Waals volume, repulsion, and London dispersion), dipole-dipole, ion-dipole, Coulombic and repulsion forces, charge-transfer complexation, and hydrogen bonding and coordination bonds. However, some of these are explained 
as different degrees of electron localization; therefore, these forces can be simplified to the van der Waals force, electrostatic interaction, and hydrogen bonding. The probable interaction can be estimated from the chemical structure of the analytes and stationary phase materials. The molecular interactions (MI) that are probably involved with retention in liquid chromatography can be explained by these solubility factors. Consistent with the concept of "like dissolves like" proposed by Henry Freiser, the retention mechanisms of chromatography are the same. The retention of a particular molecule is not due to a single factor, but rather to a combination of several factors [13,14]. Different types of chromatography demonstrate the typical molecular interaction forces.

Hydrophobic interaction was explained using alkanes which are completely saturated molecules having no specific physicochemical properties except van der Waals volume. They interact together via van der Waals forces. The alkyl phase in reversed-phase liquid chromatography is hydrophobic, and therefore, should reject adsorption of water molecules. An organic modifier may support the molecular interaction between an alkyl phase and an analyte, but works mainly to replace the analyte on the surface of the alkyl phase.

Hydrogen bonding interaction was demonstrated using alkylalcohols. The alkyl-chain length contributes to the hydrogen bonding of alkyl alcohol. The hydrogen bonding of alkyl alcohols depends on the alkyl chain length, and calorimetric experiments demonstrated that up to three methylene units can affect the hydrogen bonding. Experimentally, pentyl-bonded silica gel is chemically stable, but butyl-bonded silica gel is chemically unstable $[1,15]$. The difference may be due to the electron of silica gel oxygen like alkylalcohol oxygen.

Historically, normal-phase (NP) liquid chromatography is called as adsorption liquid chromatography, and used mainly nonaqueous eluent (organic solvent mixtures). In the early stage of liquid chromatography, a variety of packing materials were used in both nonaqueous and aqueous eluents. The retention time of analytes depended on the selection of eluent, and an analyte is eluted very quickly from the column using eluent in which the analyte readily dissolves. The dilution solvent is generally either water or n-hexane. Such approach was first demonstrated for the separation of saccharides on ion-exchange resins in 1965 where the dilution solvent was alcohol $[16,17]$. The chromatography should be the first hydrophilic interaction liquid chromatography (HILIC). Phthalate esters with longer alkyl-group were eluted faster in nonaqueous eluent, and the elution order was reversed in aqueous eluent from a variety of packing materials such as bare silica gel, chemical-bonded polar and nonpolar silica gels, ion-exchangers, and polystyrene gel [18-22]. The retention time of caffeine was shortened by increasing acetonitrile concentration; however, the retention time became longer by further increasing acetonitrile concentration $[13,23]$. These simple chromatographic results indicated that elution order is affected by selection of the eluents either aqueous or nonaqueous for polar phases including bare silica gels and ion-exchangers. Such simple examples demonstrated the interaction mechanisms in reversed-phase (RP) and ion-exchange (IX) liquid chromatographies. The main interaction in reversed-phase liquid chromatography is van der Waals force (hydrophobic interaction), and that in ion-exchange liquid chromatography is electrostatic interaction. The interaction mechanisms in NP and HILIC are the same. HILIC was proposed to explain the separation of polar compounds [24]. Presently, HILIC is a popular name in liquid chromatography; however, we have to carefully use the name based on the molecular interaction mechanisms. The majority of applications in HILIC have been performed in aqueous eluent. Therefore, the actual name should be aqueous HILIC. We can also call it as aqueous normal-phase [25]. The retained analytes are eluted by solvation; later, it was called solvophobic and replacement chromatography [26]. NP is a word to explain the balance of polarity of eluent and packing materials, and HILIC is a word to explain the retention mechanisms. Therefore, we can use both names for the same chromatography.

Coulombic force (ion-ion interaction) was studied using acetic acid and ammonia. Electrostatic energy is the main contributor to ion-pair formation. Furthermore steric hindrance was studied using amino acids. Steric hindrance cannot be directly calculated, but a lower MI energy value indicates 
lower steric hindrance in a complex. The hydrogen bonding energy values of $R$ - and $S$-amino acid complexes are lower than those of $R$ - and $R$-complexes or $S$ - and $S$-complexes.

The probable interaction can be quantitatively calculated with a molecular mechanics (MM) program using the chemical structures of analytes and model stationary phase materials $[13-15,27]$. MI calculations were first applied using simple model compounds. MM calculations can provide hydrophobic interaction, Coulombic interaction, and hydrogen bonding, as well as van der Waals (VW) energy, electrostatic (ES) energy, and hydrogen bonding (HB) energy values [15]. MI sites are indicated by changes in the atomic partial charge (apc) of contact atoms. For example, the $\Delta$ apc of hydrogen was found to be $0.002 \mathrm{AU}$ in hydrophobic interaction between two n-hexane molecules while analyzing hydrophobic interaction. The $\Delta$ apc of oxygen in diethylether was found to be 0.032 au in a study of $\pi-\pi$ interaction. The $\Delta$ apc of hydroxyl hydrogen of pentylalcohol was found to be $0.013 \mathrm{AU}$ when $\mathrm{HB}$ was analyzed between two pentylalcohols. When the ion-ion interaction was analyzed between butyric acid and pentylamine, the $\Delta$ apc values of butylic acid oxygen and pentylamine nitrogen were found to be 0.044 and $0.036 \mathrm{AU}$, respectively [28]. Especially, chiral recognition cites are clearly indicated by $\Delta \mathrm{apc}$ [15]. These MI energy values $\left(\mathrm{kcal} \mathrm{mol}^{-1}\right)$ are the sum of a solute and model phase energy values minus a complex energy value, calculated as per the following equations [15], where MIHB, MIES, and MIVW are the MI energies of hydrogen bonding (HB), electrostatic (ES), and van der Waals (VW) energy values, respectively.

$\mathrm{MIHB}=\mathrm{HB}$ (molecule A) + HB (molecule B) $-\mathrm{HB}$ (molecule A and molecule B complex),

MIES = ES (molecule A) + ES (molecule B) - ES (molecule A and molecule B complex), and

$\mathrm{MIVW}=\mathrm{VW}$ (molecule A) + VW (molecule B) $-\mathrm{VW}$ (molecule A and molecule B complex).

The relative MIHB, MIES, and MIVW values indicate their contribution levels. The alkyl-chain length effect was further analyzed using alkyl alcohols as the model phases and benzoic acid as an analyte. In this model analysis, MIES was changed as the alkyl alcohol was varied up to propyl-phase, especially for ionized benzoic acid, but MIHB was constant. This result indicated that an anion may reach a chemically bonded site of silica gel and not be repulsed from the alkyl groups. Therefore, short alkyl chain bonded silica gels are chemically unstable in water-rich eluents in reversed-phase liquid chromatography [29].

The selectivity of bonded-phase silica gels was also analyzed using the same approach to explain the differences between the hydrophilic, hydrophobic, and ion-exchange mechanisms. The model phases were pentyl-, hexenyl-, hexylamino-, and ionized hexylamino-bonded silicone trioxide. Among various polar bonded-phases silica gels, the hexylamino-bonded silica gel is stable and can be used in both aqueous hydrophilic and ion-exchange liquid chromatography with high reproducibility. Hexenyl-bonded silica gel is also used in hydrophilic interaction liquid chromatography (HILIC) $[27,30,31]$. The model compounds are toluene and benzoic acids in molecular and ionized forms. Hydrogen bonding and weak electrostatic interaction contribute to the retention in HILIC. Strong electrostatic interaction is dominant in ion-exchange liquid chromatography [30]. Further studies were carried out using model octyl-, hexenyl-, hexylamino, and hexylguanidino-bonded lead trioxide. The analytes were benzoic acid, phenol, 4-chlorophenol, 2,4-dichlorophenol, 2,4,6-trichlorophenol, benzene, toluene, and ethylbenzene. The liquid chromatography was performed using a $20 \mathrm{mM}$ sodium phosphate solution containing $50 \%$ methanol. The calculated energy values indicated the selectivity of these model phases and the retention mechanisms. These compounds were retained at the alkyl-ligands of the bonded-phases by VW interaction, and the polar groups by HB. The difference in the molecular interaction strengths were quantitatively analyzed using the calculated energy values [31].

A further study was carried out using flat model phases. The simplest model phase is a graphitized carbon phase. It consists of large, flat, polycyclic hydrocarbon constructed using $\mathrm{sp}^{2}$ carbon atoms [32]. Furthermore, $\mathrm{sp}^{3}$ carbon atoms can form a honey comb-type homogeneous support [33]. The model phase was applied to analyze the retention times of phenolic compounds [34] and aromatic acids [35] 
in addition to drug-albumin binding affinity [36]. Model ion-exchangers were constructed and the chromatographic behavior of acidic drugs on a guanidino ion-exchanger [37] and basic compounds on a carboxyl ion-exchanger [38] was studied. However, the alkyl bonded phase is dense; therefore, it was suitable for the analysis of the retention times of flat molecules such as phenolic compounds [39]. An alkyl-bonded poly silicone dioxide phase was constructed and applied to analyze phenolic compounds [40,41], acidic drugs [42], basic drugs [43], and aromatic acids as well as chromatographic behavior of steroids in normal-phase (nonaqueous HILIC) [44]. Furthermore, a large $\mathrm{sp}^{3}$ atom, lead, was used to build a model homogeneous phase, and the mew model phases were used to analyze the retention data of acidic drugs measured using a pentyl- and an octyl-bonded silica gels was analyzed. The addition of MI energy values calculated using a model solvent phase improved the in silico analysis of the retention time of acidic drugs in reversed-phase liquid chromatography [45].

\section{Definition in Liquid Chromatography}

Recently, new bonded-phase silica gels have not appeared as common packing materials for reversed-phase liquid chromatography. However, the development of new packing materials has been focused on hydrophilic interaction liquid chromatography. Hydrophilic interaction is also the main MI in normal-phase liquid chromatography. HILIC should be actually aqueous HILIC, while normal-phase liquid chromatography is actually nonaqueous HILIC. Ion-exchange liquid chromatography should be independently classified.

The packing materials for aqueous HILIC have a polar group in their structure. The simple polar group is a part of the bonded ligands in reversed-phase liquid chromatography, if the packing materials should be used in a 100\% aqueous solution. When imidazole is used as the polar group of the bonded phases, the packing materials can be used in 100\% aqueous solutions. Imidazole and other polar groups expanded the selectivity of bonded-phase silica gels. In reversed-phase systems, hydrophobic interaction is the main retention mechanism. However, the presence of additional polar groups improved the capability of hydrogen bonding and electrostatic interaction, and expanded the selectivity of bonded-phases. The drawback is the reduced the chemical stability, the same as that seen in the packing materials developed for reversed-phase systems in $100 \%$ aqueous solutions.

The retention mechanism of HILIC mode liquid chromatography is a combination of hydrophilic interaction and Lewis acid-base interaction. Hydrophilic interaction is based on hydrogen bonding and the electrostatic force. The Lewis acid-base interaction is also due to electrostatic forces. The electrostatic force in the HILIC mechanism is like contact charge transfer: the energy level is smaller than the hydrogen bonding energy. However, the electrostatic energy level is higher in the ion-exchange mechanism. Such a difference is quantitatively described by using hydrogen bonding and electrostatic energy values calculated using the MM program. The $\mathrm{H}$ in HILIC means hydrophilic and is the opposite of hydrophobic. In general, hydrophobic interaction is mainly used to explain the retention mechanisms in reversed-phase liquid chromatography. Reversed-phase liquid chromatography is the inverse of normal-phase liquid chromatography. However, it seems that HILIC is not the same as normal-phase liquid chromatography. If hydrophobic interaction is eliminated from the retention mechanisms in liquid chromatography, the remaining interactions are hydrogen bonding and Coulombic interaction. Coulombic interaction is the main mechanism in ion-exchange liquid chromatography, whereas hydrogen bonding is the main mechanism in normal-phase liquid chromatography [15]. The difference between HILIC and normal-phase liquid chromatography seems to be the properties of solvents used as components of the eluent. In general, only organic solvents are used in normal-phase liquid chromatography; however, water-saturated organic solvents are often used to improve the separation. Since "hydrophilic" means not hydrophobic, the hydrophilic interaction includes hydrogen bonding and Coulombic interaction. That is, HILIC is aqueous HILIC and normal-phase liquid chromatography is nonaqueous HILIC. Ion-exchange liquid chromatography is independent of HILIC. 
Ion-exchangers have a longer history than modern bonded-phases. The first automated high-performance liquid chromatograph was an amino acid analyzer. The current degree of performance is more than 1000 times higher based on the retention times. However, current silica core ion-exchangers are chemically unstable compared to the classic ion-exchange resins. The chemical stability of ion-exchange resins used for ion-chromatography is still superior to that of current bonded-phase ion-exchangers. However, a variety of ion-exchangers have been developed to meet the requirement of selective purification from a complex matrix. Especially, various ionic liquids (ILs) based on imidazole structures have been synthesized and used for extraction and separation as liquid and immobilized forms.

Therefore, ion-exchange liquid chromatography should remain classified as an independent chromatographic method. The retention mechanism of ion-exchange liquid chromatography occurs via the exchange of ions interacting (adsorbed) with the ion-exchange groups of the ion-exchangers. However, the molecular forms of the analytes are retained on ion-exchangers by Lewis acid-base (charge transfer) interaction, as well as by hydrogen bonding. The chemical structures of model bonded ligands are shown in Figure 1 and their electron density maps are shown in Figure 2 where electrophilic susceptibility is shown for their easy visualization. The hydrophobicity of up to C4 alkyl-chains is affected by siloxane oxygen. The reason can be observed by the electron density of the end methyl group indicated in circle from C1 (methyl) to C6 (hexyl). Up to C3, the methyl group showed different color compare to those of beyond $\mathrm{C} 4$. The electron density maps of alkyl groups supported the results obtained in the study of the alkyl group contribution to the polar group interaction as well as that to HB of alkyl alcohols [17]. Other model ligands in the Figure 1 are a part of the chemically stable bonded silica gels. The pentyl-ligand provided stability to the bonded-phase silica gels [1].

The hexenyl ( $\mathrm{HxNy}$ in Figure 1)-bonded silica gel can be used in both hydrophobic (reversed-phase) and hydrophilic interaction liquid chromatographies. In acidic condition, the molecular form benzoic acid interacted via hydrogen bonding with the vinyl-group of model hexenyl-phase, but not at high $\mathrm{pH}$. Ionized benzoic acid did not show the strong interaction with this hexenyl-bonded silica gel. However, both molecular and ionized form anilines interacted with the vinyl group of model hexenyl-phase via hydrogen bonding. The electron density maps of complexes are shown in Figure 3. Figure 3A,B depicts the complexes between hexenyl and benzoic acid (A) or ionized aniline (B).

A hexylamino-phase may contribute for both HILIC and ion-exchange liquid chromatography. The amino group formed hydrogen bonding with benzoic acid carboxyl-group but not with the ionized form. The amino group also interacted with ionized amino group of aniline via electrostatic interaction. The hexylamino group formed strong hydrogen bonding with benzoic acid at low $\mathrm{pH}$, and tightly contacted with benzoic acid at neutral $\mathrm{pH}$ via electrostatic interaction. However, it did not show strong interaction at high $\mathrm{pH}$. The ionized amino group demonstrated hydrogen bonding with toluene at low $\mathrm{pH}$. This is an interaction between amino-group hydrogen and toluene phenyl-group [30]. The example of electron density maps of these complexes are shown in Figure 3. Figure $3 \mathrm{C}$ is a complex between hexylamine and benzoic acid, and 3D is that between ionized aniline and ionized benzoic acid (ion-ion interaction).

Figure 3G is enantiomer (3F) recognition of chiral phase (3E). The comparison of electron density of these molecules and that of their complexes was clearly visualized these complex conformations. The detail of their interaction strength can be obtained as MI energy values. However, both benzoic acid and aniline interacted with these model phases via hydrophobic interaction indicated by the VW energy value difference. When these molecules were located at free space, they formed the side-by-side complexes. However, these ligands are densely bonded and such free rotation of bonded phase should be limited in HILIC condition. The free movement of ligands may be occurred in organic modifier rich reversed-phase liquid chromatography [29]. 


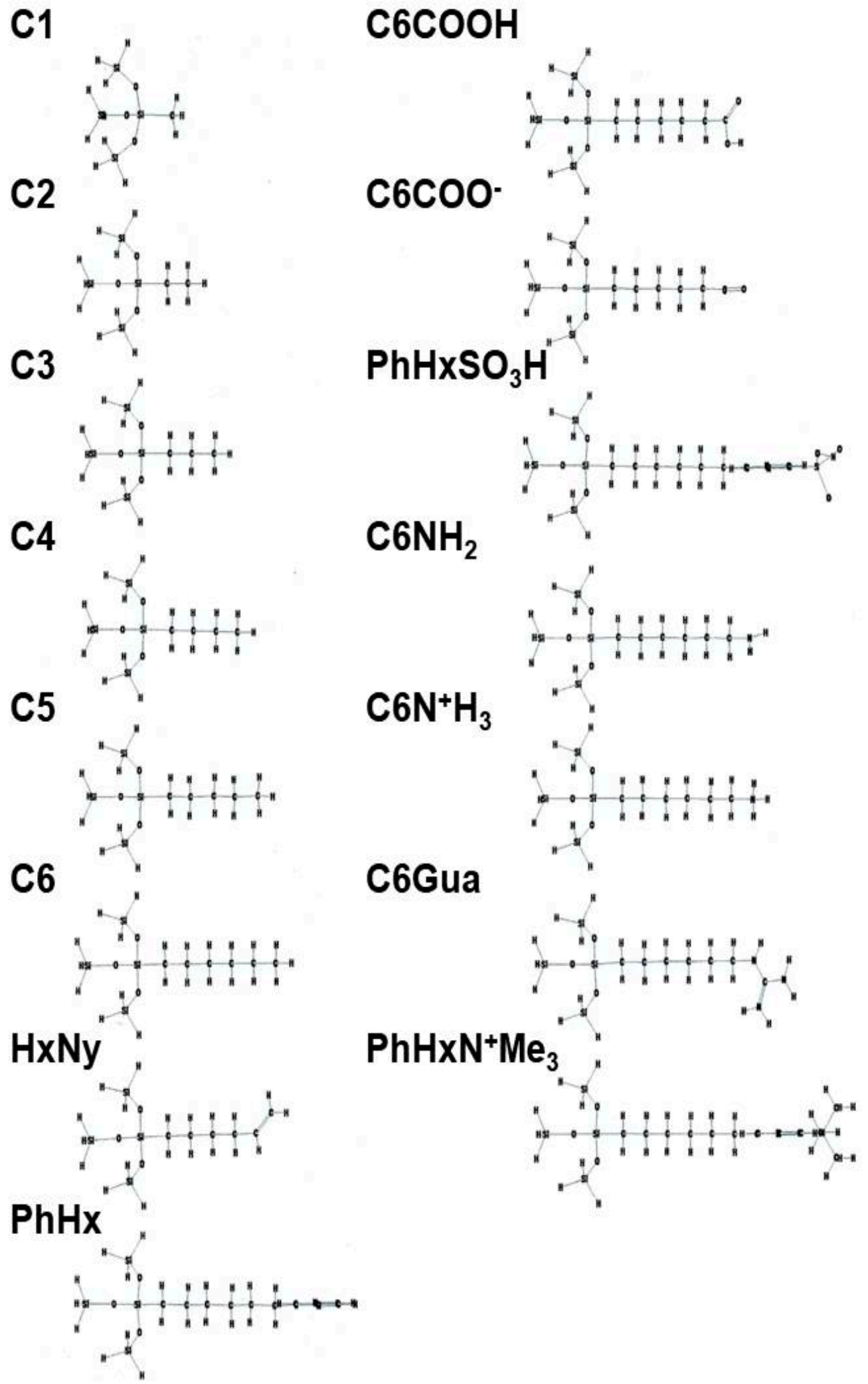

Figure 1. The chemical structure of model compounds, C1-C6: methyl-hexyl bonded; HxNy and $\mathrm{PhHx}$ : hexenyl- and phenylhexyl-bonded; $\mathrm{C} 6 \mathrm{COOH}$ and $\mathrm{C}_{6} \mathrm{COO}^{-}$: molecular and ionized hexyl carboxyl-bonded; $\mathrm{C}_{6} \mathrm{NH}_{2}$ and $\mathrm{C}_{6} \mathrm{~N}^{+} \mathrm{H}_{3}$ : molecular and ionzed hexylamino-bonded; $\mathrm{PhHxSO}_{3} \mathrm{H}$ and $\mathrm{PhHxN}^{+} \mathrm{Me}_{3}$; 6 G 6 ua: hexylguadinino-bonded; phenylhexyl-modified sulfonateand trimethylamino-bonded silicone trioxide, respectively. 


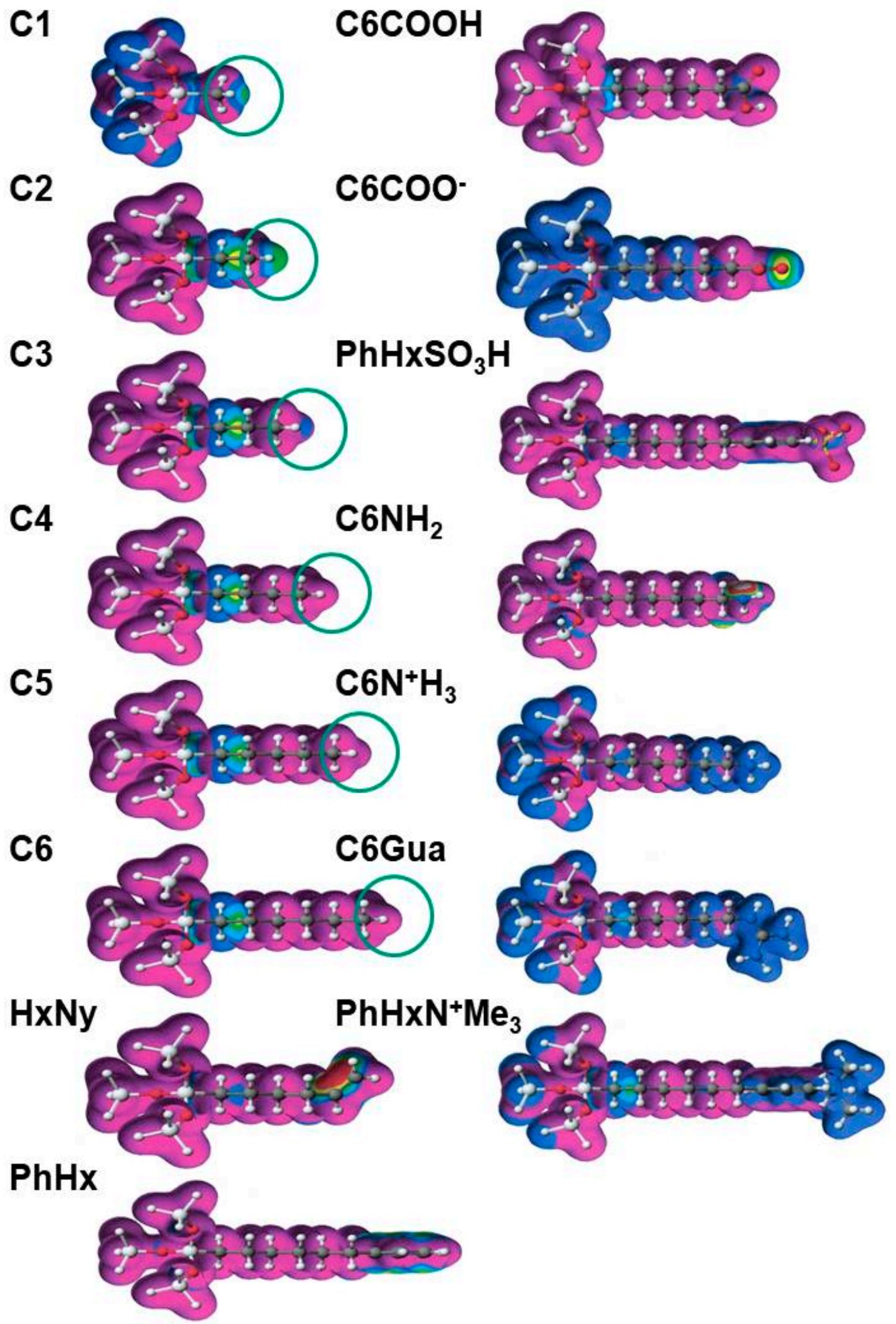

Figure 2. Electron density (electrophilic susceptibility) of model ligands. For an explain of the symbols see Figure 1. Electron density indicates from high to low (white $>$ red $>$ yellow $>$ light green $>$ light blue $>$ blue $>$ magenta $>$ purple). Ionization changes the electron density from magenta to blue (see $\mathrm{C} 6 \mathrm{COOH}$ and $\mathrm{C}_{6} \mathrm{COO}^{-}$). Cationic and anionic indicate the opposite electron density $\left(\right.$see $\mathrm{C}_{6} \mathrm{~N}^{+} \mathrm{H}_{3}$, C6Gua, and $\left.\mathrm{PhHxN}{ }^{+} \mathrm{Me}_{3}\right)$. 


\section{Molecular interaction complexes}
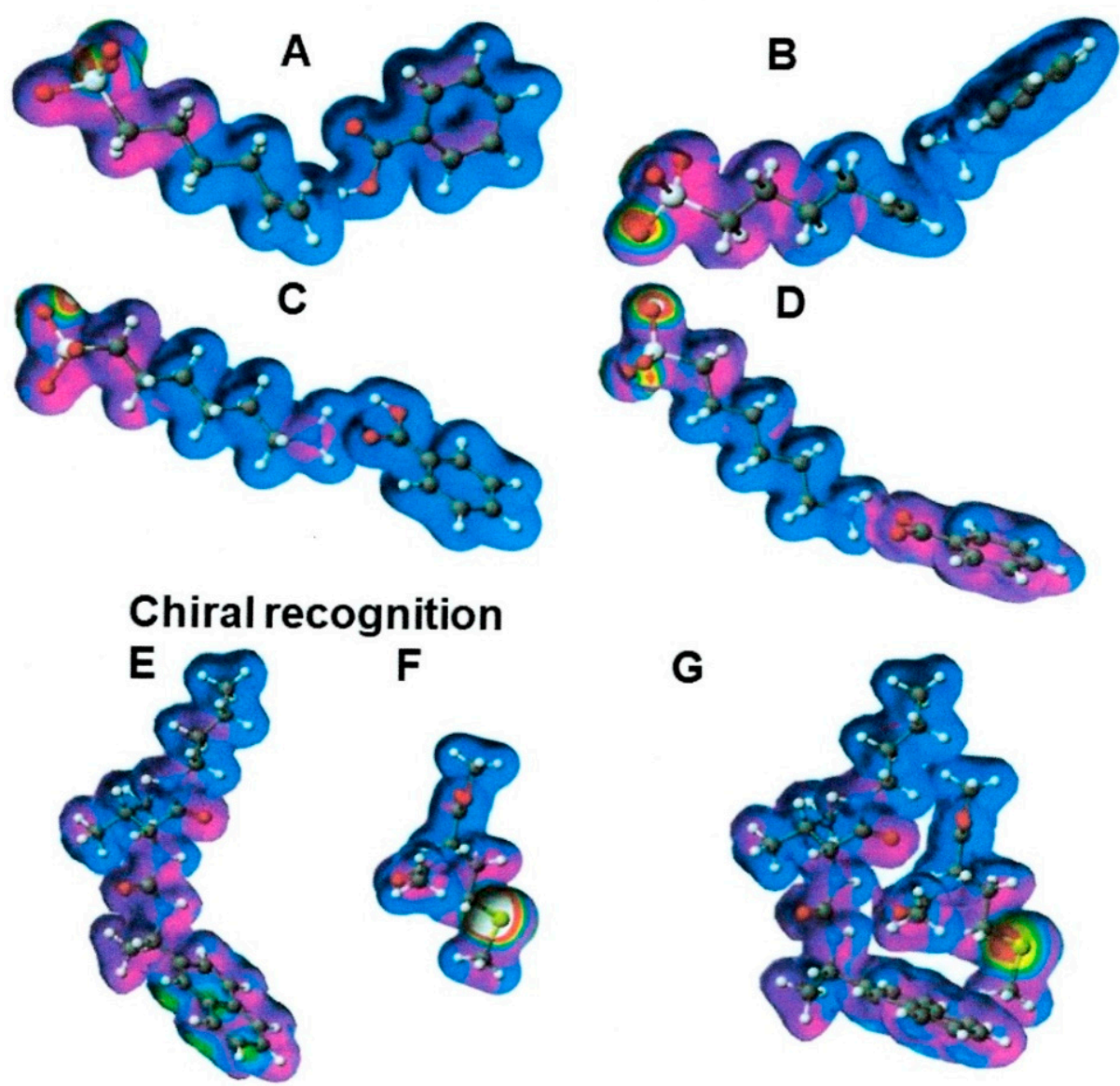

Figure 3. Molecular interaction form and imidazolium ligand, $\mathrm{A}: \mathrm{HxNy}$ and benzoic acid complex. B: $\mathrm{HxNy}$ and ionized aniline complex. C: $\mathrm{C} 6 \mathrm{NH}_{2}$ and benzoic acid complex; D: $\mathrm{C}_{6} \mathrm{~N}^{+} \mathrm{H}_{3}$ and ionized benzoic acid ion-pair formation. G: enantiomer recognition of $\mathrm{E}(N-(R)-1-(\alpha$-naphtyl)ethylamino carboxyl-(S)-valylaminobutane) with F: ((R)-N-acetylmethionine) ([15], p. 185). For an explanation of Figure color see Figure 2.

\section{New Developments in Bonded-Phases}

Ionic liquids (liquid ion-exchangers, IL) have been used for the extraction of a variety of both inorganic and organic compounds and also as stationary phases in chromatography since 1969 . The structures of Ils can vary based on their polar or nonpolar skeletons and conjugated ion-exchange groups. ILs are the subject of over 4500 chromatography related publications including more than 213 reviews and book chapters. However, the rate of publications has accelerated since 2004 due to further demands for selective concentration methods leading to the synthesis of new ILs.

As described in some past reviews [46,47], ILs are unique and fascinating non-molecular solvents with unique characteristics such as a negligible vapor pressure associated with a high thermal stability, tunable viscosity, and miscibility with water and organic solvents. They generally consist of an organic cation and inorganic or organic anion. ILs are supposed to be liquid in most environmental conditions [46-48]. However, ILs can be used as both adsorbent and solvent depending on the physical conditions. They can be used for liquid-liquid extraction (concentration), while the immobilized materials can be used for liquid-solid extraction (concentration). This physical flexibility permits ILs to be used for a variety of analytical methods.

ILs have been used in sensing/biosensing and separations applications as stimuli-responsive polymers with unique characteristics [46]. Room temperature ionic liquids are good solvents for nonionic compounds with different blend of intermolecular interactions, as shown by solvatochromic 
measurements and the system constants of the solvation parameter model. They are used as mobile phases or mobile phase additives in chromatography [47]. Immobilized ILs are sorbents with the properties of solvents. A magnetic IL was developed and its specificity allowed it to be applied for useful sample collectors [48].

The miscibility of ILs with water permits the reduction of organic solvent concentrations; therefore, analytical methods using IL can be called greener chemistry [49-52]. Different QSAR studies have been performed on ILs and highlighted their safety, health, and environmental issues [47]. ILs have been used for small scale extraction and reversed-phase HPLC systems. ILs are not intrinsically nontoxic agents. Different QSAR studies have been performed on ILs and highlighted the safety, health, and environmental issues $[49,50]$. Extraction-separation processes using aqueous IL solutions have been suggested from a green chemistry perspective [51]. ILs are proposed for greener, faster, and simpler sample preparation [52]. The recent advances in greener RP-HPLC methods dedicated to pharmaceutical analysis are based on the use of alternative solvents [53].

\section{Typical Structures of Bonded-Phase for HILIC}

Since 36 structures of ILs were illustrated [54] in 2012, many ILs have been synthesized by covalently attaching an imidazole group to the silica surface. Some ILs have been polymerized on the surface of solid supports. Some of them are zwitter ions [55]. Based on their physical and chemical divisibility, ILs have been used for various microextraction techniques. One drop liquid-liquid extraction, surface coated wire, and beads adsorption methods have been applied as microextraction techniques [56-62]. The practical applications of IL-nanomaterial hybrids for the development of analytical and preconcentration techniques were reviewed [58]. The properties and diversity of IL applications were described, especially for solid phase microextraction [59]. An improvement in the extraction performance of chromatographic materials might be reflected in the use of ILs for the stationary phase [60]. A stainless steel fiber was coated with a polymeric IL through covalent bonds for solid-phase extraction of polycyclic aromatic hydrocarbons in water [61]. Three IL-functionalized silica materials-imidazolium, $\mathrm{N}$-methylimidazoliun and 1-alkyl-3-(propyl-3-sulfonate) imidazolium-were synthesized and applied to the solid-phase extraction of organic acids, amines, and aldehydes in atmospheric aerosol particles. Mechanisms were proposed to explain their selective adsorption [62]. The electron density of model imidazolium phases is shown in Figure 3A,B. Figure 3A is a model $\mathrm{N}$-methylimidazolium [62] and 3B is a model $\mathrm{N}$-(propyl-3-sulfonate) imidazoliun phase [63]. The imidazole ring is polar and miscible with water and interacts with analyte polar group. The additional substitutes will improve the selectivity. The selective interaction can be visualized using electron density map for the easy explanation as shown the examples in Figure 4.
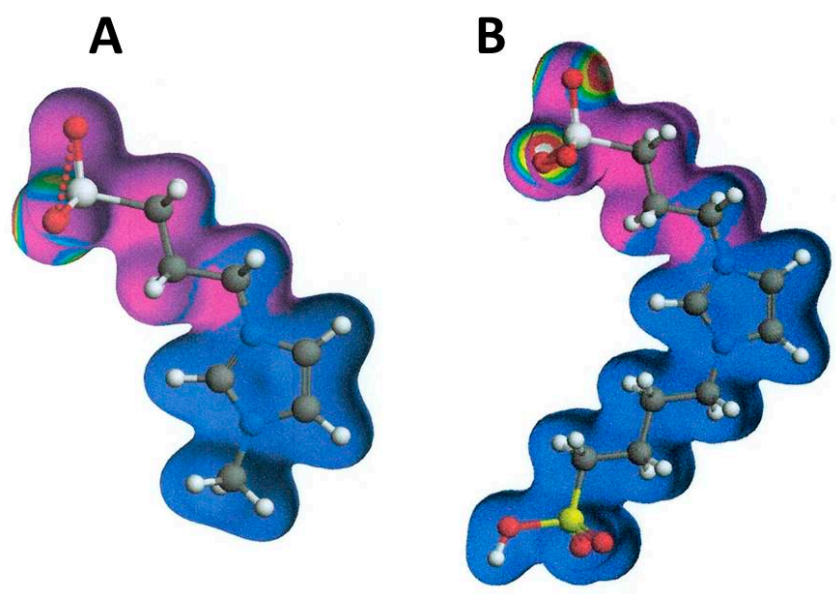

Figure 4. Imidazolium ligands: (A) imidazolium ligand [62] and (B) imidazoium zwitter ion ligand [63]. For an explanation of the color used see Figure 2. 
ILs can be used like ion-pair reagents due to the miscibility with water [63-68]. Imidazolium-based ILs have been used as mobile phase additives [67] and modifiers [68]. ILs were also used as a silanol suppressor to eliminate the silanol effect that causes tailing of basic compounds on silica-based packing materials. The physical chemistry of the stationary phases in liquid chromatography has been discussed to explain the use of ILs as silanol suppressors [69]. ILs have been immobilized for practical use as stationary phases in liquid chromatography [70-76]. A surface-initiated radical chain-transfer polymerization method was applied with 1-vinyl-3-octadecylimidazolium bromide as an IL monomer. The Br-counter anion was then exchanged for methyl orange via an in-column process [70]. Twenty-one surface-confined IL stationary phases had been developed by 2011. Their preparation, chromatographic behavior, and analytical performance were summarized [71]. The preparation and application of IL-modified stationary phases in HPLC was described [72]. Imidazolium-based zwitter-ionic stationary phases were synthesized using thiolene click chemistry [73]. ILs have been immobilized as stationary phases for liquid chromatography [74]. The optimization of HPLC conditions and parameters for the chiral resolution of racemic drugs on macrocyclic glycopeptide-based chiral stationary phases was discussed [75]. The feasibility of immobilized IL phases has been described [76].

Polar groups of ILs are suitable for HILIC [77-79]. Specific structures have been used for enantiomer separations [80-83]. Furthermore, ILs have been used to synthesize monolithic columns, and the incorporation of ILs in porous monoliths increased their selectivity $[84,85]$.

The wide range of hydrophobicity, ionic characterization, and steric hindrance has been used for chromatography in a variety of applications, such as bioactive compounds [86-91], natural products, foods, drugs, and fine chemicals [92-94], including polychlorinated biphenyls, alkylphenols, and parabens, $\mathrm{PAH}$, and phthalate $[95,96]$. An interesting approach was proposed for applications in drug delivery using drug ILs [97]. They were used for extraction of bioactive compounds in plants [88], and also as extraction solvents, for separation and preconcentration in chromatography [86]. Analytical methods using sphingosine 1-phosphate modulators in various biological matrices were reviewed including sample processing and chromatography [89]. Polymeric ILs have been used for the extraction of natural products, foods, drugs, and fine chemicals [90]; for microextraction techniques in food analysis [94]; and as new sorbents for SPME [96]. The introduction of third generation ILs into the pharmaceutical world may offer more design options. Active pharmaceutical ingredients can be readily converted into ILs, generally called drug ILs. These are also referred to as designer solvents, as the design of a liquid salt can be carried out to improve some properties such as viscosity, hydrophilicity, and many other chemical and physical properties; because of this tunable nature ILs have many applications in drug delivery [97]. Free-form ILs are also used for counter current chromatography, because they have high sample loading capacity and are suitable for the purification of biorelated compounds $[98,99]$.

The difference of retention mechanisms of hydrophobic (reversed-phase) and hydrophilic liquid chromatography was quantitatively described using simple MM calculations. The MIVW was predominant for hydrophobic interaction liquid chromatography, and MI HB was predominant for HILIC. MIES was predominant for ion-exchange liquid chromatography. The contribution of MIES for HILIC was weak and that for ion-exchange was strong. Furthermore, the direct contact sites were indicated using atomic partial charge [15]. Three dimensional structures of model hexyland hexenyl-bonded silica gels are shown in Figure 5. Quinizarine carboxyl group contacts with the vinyl group of hexenyl ligands (Figure 5A), and ionized quinizarine remains on the surface of the hexyl-bonded phase (Figure 5B). Such demonstrations using simple molecules support the detail of the molecular interaction mechanisms. 
A

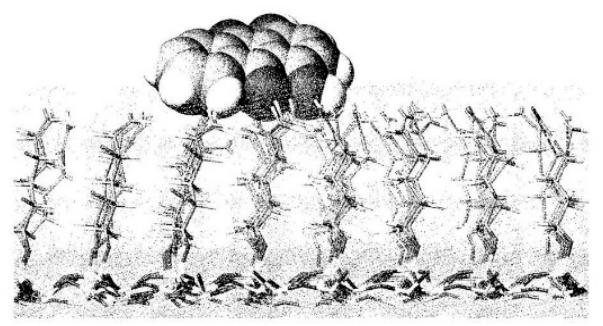

B

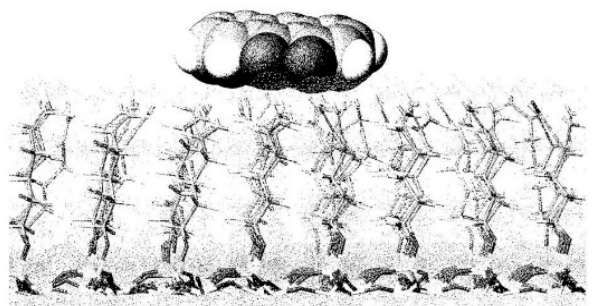

Figure 5. Model hexyl- and hexenyl-bonded silica gels: (A) Quinizarine carboxyl-group contacts with hexenyl vinyl group and (B) ionized quinizarine stays at top of hexyl-bonded phase. Black ball: oxygene. Gray ball: carbon. White Ball: hydrogen. Model phase atoms shown as dot form.

\section{Superficially Porous (Core-Shell and Fused-Core) Packing Materials}

A variety of packing materials using silica gels have been developed and commercialized since the beginning of high-performance liquid chromatography. At the beginning, it was called high-pressure liquid chromatography, much as we use the term ultrahigh-pressure liquid chromatography (UHPLC) for new systems. $\mu$ Bondapack from Waters is synthesized based on a porous silica gel, and many bonded-phase silica gels exhibit similar performance. On the other hand, Zorbax from DuPont (previous manufacturer) is synthesized from nonporous materials; various ligands are bonded to achieve high performance separations. According to the van Deemter equation, reducing the height equivalent to theoretical plate (HETP) is required for an efficient separation. The HETP value can be expressed as the sum of (A) eddy diffusion, (B) longitudinal diffusions, and (C) resistance to mass transport in the stationary and mobile phases.

A: Eddy diffusion is a result of the presence of particles of stationary phase material in a column, and depends on the stationary phase conditions, shape of the column, and the structure of stationary phase material. The influence of the stationary phase material can be divided into the particle size, the shape of the particles, and the porosity of the particles. Eddy diffusion depends on the irregularity of the particle (particle shape) and the column material: the relative effect will always increase as the column diameter decreases. The eddy diffusion will be limited when small spherical particles are uniformly packed.

B: Longitudinal diffusion can be reduced by an increase in the viscosity of the solvent or by a decrease in the temperature. Longitudinal diffusion can thus be reduced by decreasing the diffusion coefficient and increasing the flow rate; however, these two actions are counter-effective in liquid chromatography because of the mass transport term.

C: This diffusion effect results from the mass transfer of the analyte between the stationary and mobile phases, and is a fundamental phenomenon in high performance liquid chromatography. The injected analyte molecules are first present in the mobile phase. They are then transferred back and forth from the stationary phase in order to interact. This process is repeated along the column, from the inlet to outlet. The diffusion is affected by a parameter that depends on the type of stationary phase used, e.g., spherical, irregular, fiber, or porous. The average residence time of analyte molecules in the stationary phase is related to the thickness of the stationary phase and the diffusion constant of the analyte molecules in the stationary phase. This means that a thinner or shallower stationary phase gives higher performance in liquid chromatography. However, the sample loading capacity in thinner stationary phase is small.

The smaller the particle size the more efficient the theoretical plate numbers. Jorgenson used small porous silica gels to obtain very high efficiency packed columns based on the van Deemter equation. However, it required very high pressure, so-called ultrahigh pressure. It is a challenge to reduce the operation pressure without decreasing the separation power. One potential solution to this problem is the utilization of modern pellicular-type packing materials. The difference from (classic) Zipax is the size of the core material, which is smaller than that of Zipax. Another pellicular-type of packing material uses a small, nonporous silica cores, different from classic Corasil-like materials [100-102]. Fast analysis of ions was achieved by the development of pellicular-type ion-exchangers. The new 
types of ion-exchange resins demonstrated the quick transfer of analytes and were marketed as the heart of ion-chromatography [103]. The difference between modern and classic packing materials can be easily estimated from the difference in their surface areas. The performance follows the present superficially porous type packing materials.

Superficially porous packing (SPP) materials are one solution if the retention capacity is practically equivalent to that of fully porous packing (FPP) materials. The surface of nonporous beads can be chemically-modified to improve the quick mass transport of analytes between the surface of the packing materials and the mobile phases. The core size of modern pellicular-type materials is very small based on the availability of nonporous monodispersive silica gels. Therefore, the total surface area of packing materials inside the column becomes competitive with porous packing materials [3-11].

First, small size silica gels were attached on the surface of large nonporous silica gels and marketed as Zipax. The advanced materials were also synthesized by the Kirkland group [104]. The main merit of this synthesis method is the easy control over the surface pore size. Another pellicular-type silica gel marketed by Waters was Corasil, and the advanced products were also synthesized by Waters [105]. Similar approaches were developed, and several modern pellicular-type silica gels were synthesized and are now available. Another approach is to synthesize a porous silica gel film on the surface of a nonporous core silica gel. Various thick layers can be deposited on both inorganic and organic core materials.

The surface of nonporous beads was chemically-modified to improve the quick mass transport of analytes between the surface of the packing materials and the mobile phases and also increases the selectivity. Previously, these packing materials were called pellicular-type packing materials. However, the retention capacity of previous packing materials is very low compared to that of porous packing materials. The thinner the surface layer, the more the efficiency is increased, but the lower the loading capacity. The core size of modern pellicular-type materials is very small based on the availability of nonporous monodispersive silica gels. Therefore, the total surface area of the packing materials inside the column has becomes competitive with that of porous packing materials.

\subsection{Synthesis of Superficially Porous Silica Gels}

There are many methods of synthesizing superficially-bonded silica gels. These synthesis methods are classified into three categories:

1. Attaching small nonporous particles on the surface of nonporous core silica gels $[104,106]$ : Nanoparticles in solution are fused to the surface of the nonporous silica core using urea-formaldehyde, and the remaining organics are removed by high temperature treatment [104]. A SPP of $1.1 \mu \mathrm{m}$ was synthesized by depositing colloidal silica [106]. Nanodiamond SPP was also developed. The chemical ( $\mathrm{pH} 1-13)$ and thermal $\left(<100^{\circ} \mathrm{C}\right)$ stability may make them especially opportunity to use for special separations [107].

2. Growing porous silica gels or whiskers on the surface of nonporous core silica gels [108-121]: Many synthesis methods are focused on growing porous silica gels or silica whiskers on the surface of nonporous core silica gels. However, the reaction methods used to do this are similar and based on polymerizing organic silicones such as tetraethoxysilicone and tetramethoxysilicone in solutions containing cationic surfactants. The selection of additives and different physical conditions produced a variety of SPPs [108-119].

3. Further etching the surface of SPPs [111,116,122]: SPPs were synthesized, and the pore size was enlarged via acid-refluxing [116]. The SPP was synthesized using a pseudomorphic transformation. The outer-layer of solid silica was dissolved and reprecipitated to form a porous layer during this process [122], thus growing a porous silica layer from organic silicones onto the surface of a nonporous silica gel. Further washing using an acidic or basic solution can be used to increase pore size [111].

The schematic models of above three types of SPPOs are shown in Figure 6. The performance of a $2.7 \mu \mathrm{m}$ SPP-packed column was equivalent to that of a $1.8 \mu \mathrm{m}$ FPP; however, the pressure was 
approximately half [3]. The relation between column size and injection capacity using SPP was studied and it was concluded that it could be done, but revalidation was recommended [4]. Sub-2 $\mu \mathrm{m}$ SPP-packed columns demonstrated higher efficiency with high pressure; however, a sub-3 $\mu \mathrm{m}$ SPP-packed column could be a more practical choice due to its low column pressure and the availability of ordinary HPLC systems [5].
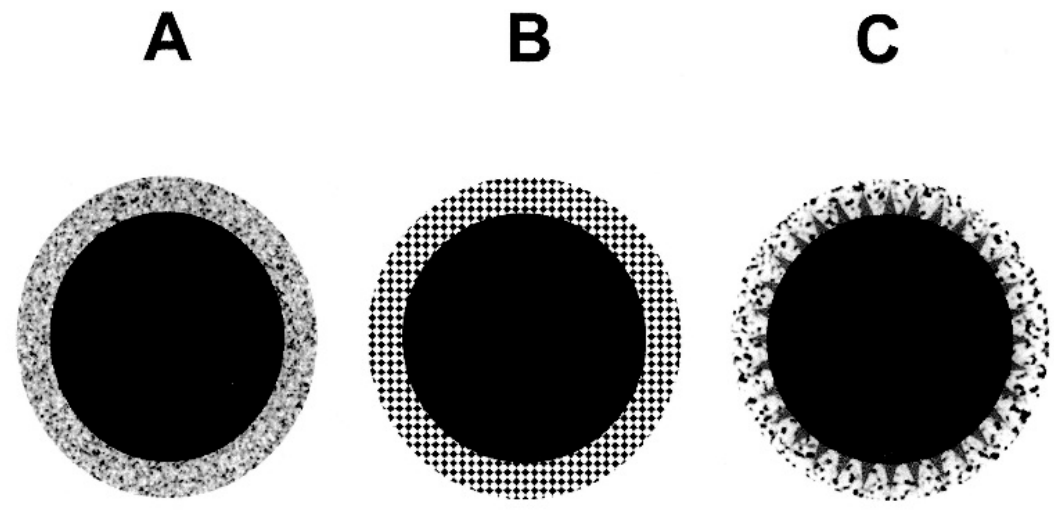

Figure 6. Model superficially porous silica gels. A: synthesized porous silica gel on the surface of nonporous core silica gel. B: small nonporous silica gels are attached on the surface of nonporous core silica gel. C: etching the dense surface porous silica gel or whisker silica gels to increase the pore size.

\subsection{Performance of Superficially Porous Packing Materials based on the van Deemter Equation}

The column shape and the physical properties of packing materials have been analyzed based on the van Deemter equation [123-132]. The particle size distribution was studied for its contribution to band broadening in chromatographic columns [123] and effects in capillary columns [124]. Diffusion was theoretically explained along columns packed with FPP and SPP materials [125,126]. The extra-column band broadening inside small size columns using SPP was investigated [127]. The mass transfer kinetics of the different contributions to the HETP were analyzed, and specifically described for small particle packing materials [128-132].

\subsection{Applications of Superficially Porous Packing Materials}

New bonded phases such as $N$-hydroxyethyliminodiacetic acid for chromatography of 14 lanthanides and yttrium [133], anthracenyl-phase for the aromatic selectivity [134] have been developed. A variety of brush-type chiral stationary phases [135] were synthesized, and a hydroxypropyl- $\beta$-cyclodextrin-phase [136] and a quinine-phase [137] were also synthesized and their high-speed separation was demonstrated by comparison with their related FPP packing materials. Ultrafast chiral separation using SPP was also demonstrated [138]. The superiority of SPP materials for chromatography of macromolecules (biomolecules) was described [139-141]. This high performance was applied for food analysis [142].

\section{Conclusions}

Chromatographic separation is achieved by the use of a high plate number column and the selectivity of the stationary phase. The explanation of the theoretical plate number is the physical part, and the selective separation is the chemical part of chromatographic science.

Understanding the fundamental retention mechanisms in chromatography allows the researcher to select a suitable packing material and chromatographic conditions, such as the selection of eluent components, the practical column size, and the required instruments. The probable interactions can be recognized from the chemical structures of the analytes and stationary phase materials and the chromatography modes [14,15].

Chromatographic retention is driven by molecular interaction between an analyte and a stationary phase. Such interaction is considered a Lewis acid-base interaction, and the interaction is induced 
at chromatographic conditions. The phenomenon is similar to a contact charge transfer. An electron rich site and an electron poor site are attracted to each other but do not transfer electrons as in organic reactions. Quantitative explanations can be achieved using computational chemical calculations (in silico). The molecular interaction forces are a combination of solubility factors, and can be obtained as van der Waals, hydrogen bonding and electrostatic energy values after molecular mechanics calculations. Steric hindrance must be considered for chiral and affinity liquid chromatographies [15]. The typical interaction site is found from the atomic partial charge of contact atoms. Figures 2-4 showed the electron localization of model phases.

Van der Waals interaction is predominant for hydrophobic interaction (reversed-phase) liquid chromatography, and hydrogen bonding is predominant for hydrophilic interaction liquid chromatography. Up to 5 units of alkyl-chain methylene can affect the hydrophobicity of alkyl chains [29]. Hydrophilic interaction is based on hydrogen bonding and electrostatic forces. Ion-exchange is also driven by electrostatic forces. The difference is in the degree of electrostatic force. The electrostatic force in the HILIC mechanism is like the contact charge transfer: the energy level is lower than the hydrogen bonding energy. However, the electrostatic energy level is higher in the ion-exchange mechanism.

Such a complementary approach (computational chemical analysis) is a promising technique with the potential to analyze quantitatively the mechanisms of molecular interaction between analytes and solid phases, especially given the feasibility of modeling three-dimensional structures of biological macromolecules, such as proteins. Importantly, this technology can be easily used to study the retention mechanisms in chromatography for a variety of phases [28].

Therefore, combining chromatography and computational chemistry offers new possibilities in developing a quantitative description of molecule interaction relevant to analytical chemistry. Prediction of boiling point, dissociation constant, and albumin-drug binding affinity were demonstrated as practical applications of in silico chromatography [15]. Furthermore, a combination of quantitative molecular recognition analysis and electron transfer studies permits the quantitative analysis of enzyme reaction mechanisms [15].

Conflicts of Interest: The author declares no conflicts of interest.

\section{References}

1. Hanai, T. New developments in liquid-chromatographic stationary phases. Adv. Chromatogr. 2000, 40, 315-357. [PubMed]

2. Ahmed, A.; Skinley, K.; Herodotou, S.; Zhang, H. Core-shell microspheres with porous nanostructured shells for liquid chromatography. Sep. Sci. 2017, 41, 99-124. [CrossRef] [PubMed]

3. Bell, D.S. Current state of superficially porous particle technology in liquid chromatography. LCEGC 2015, 33, 386-395.

4. Webster, G.K.; Gragg, M.A. Scaling LC methods using superficially porous particle stationary phases. LCEGC 2018, 36, 184-193.

5. Bell, D.S.; Wiest, L.; Liang, S.-H.; Li, D. When do we need sub-2 $\mathrm{m}$ superficially porous particles for liquid chromatography. LCEGC 2018, 36, 436-439.

6. Fekete, S.; Oláh, E.; Fekete, J. Fast liquid chromatography: The domination of core-shell and very fine particles. J. Chromatogr. A 2012, 1228, 57-71. [CrossRef]

7. Wang, X.; Barber, W.E.; Lon, W.J. Applications of superficially porous particles: High speed, high efficiency or both? J. Chromatogr. A 2012, 1228, 72-88. [CrossRef] [PubMed]

8. Nesterenko, E.P.; Nesterenko, P.N.; Connolly, D.; He, X.; Floris, P.; Duffy, E.; Paull, B. Nano-particle modified stationary phases for high-performance liquid chromatography. Analyst 2013, 138, 4229-4254. [CrossRef] [PubMed]

9. Walter, T.H.; Andrews, R.W. Recent innovations in UHPLC columns and instrumentation. $\operatorname{Tr} A C$ 2014, 63, 14-20. [CrossRef] 
10. Hayes, R.; Ahmed, A.; Edge, T.; Zhang, H. Core-shell particles: Preparation, fundamentals and applications in high performance liquid chromatography. J. Chromatogr. A 2014, 1357, 36-52. [CrossRef] [PubMed]

11. González-Ruiz, V.; Olives, A.I.; Martín, M.A. Core-shell particles lead the way to renewing high-performance liquid chromatography. TrAC 2015, 64, 17-28. [CrossRef]

12. Vanderheyden, Y.; Broeckhoven, K.; Desmet, G. Peak deconvolution to correctly assess the band broadening of chromatographic columns. J. Chromatogr. A 2016, 1465, 126-142. [CrossRef] [PubMed]

13. Hanai, T. Basic selection method of stationary and mobile phases in liquid chromatography. In Separation System in Chromatography, APPROACH and Selection Methods; Hara, S., Mori, S., Hanai, T., Eds.; Maruzen: Tokyo, Japan, 1981; pp. 121-156. ISBN 4-621-02586-4.

14. Hanai, T. HPLC, A Practical Guide; Royal Society of Chemistry: Cambridge, UK, 1999; pp. 1-134. ISBN 0-85404-515-5.

15. Hanai, T. Quantitative in Silico Chromatography: Computational Modeling of Molecular Interactions; Royal Society of Chemistry: Cambridge, UK, 2014; pp. 1-338. ISBN 978-1-84973-991-7.

16. Arwidi, B.; Samuelson, O. Partition chromatography of sugars on ion-exchange resins. Svensk Kemish Tidskift $1965,77,2$.

17. Larsson, L.-I.; Samuelson, O. An automated procedure for separation of monosaccharides on ion exchange resins. Acta Chem. Scand. 1965, 19, 1357-1364. [CrossRef]

18. Funasaka, W.; Hanai, T. The relationship between molecular structure and chromatographic behavior, and the application of high-speed liquid chromatography. In High-speed Liquid Chromatography; Hatano, H., Ed.; Nankodo: Tokyo, Japan, 1973; pp. 153-167.

19. Funasaka, W.; Hanai, T.; Fujimura, K. High speed liquid chromatographic separations of phthalic esters, carbohydrates, TCA organic acids, and organic mercury compounds. J. Chromatogr. Sci. 1974, 12, 517-520. [CrossRef]

20. Funusaka, W.; Hanai, T.; Matsumoto, T.; Fujimura, K.; Ando, T. Nonaqueous solvent chromatography. IV. Effects of solvents and ion-exchange resins on adsorption mechanisms and their application in high-speed liquid chromatography. J. Chromatogr. A 1974, 88, 87-97.

21. Hanai, T.; Fujimura, K. Non-aqueous solvent chromatography. V: The comparison of organic and inorganic adsorbents. J. Chromatogr. Sci. 1976, 14, 140-143. [CrossRef]

22. Hanai, T.; Hatano, H. Experimental High Speed Liquid Chromatography; Kagakudojin: Kyoto, Japan, 1977; pp. 1-265.

23. Hanai, T.; Hatano, H. New Experimental High Speed Liquid Chromatography; Kagakudojin: Kyoto, Japan, 1988; pp. 1-338.

24. Alpert, A.J. Hydrophilic-interaction chromatography for the separation of peptides, nucleic acids and other polar compounds. J. Chromatogr. A 1990, 499, 177-196. [CrossRef]

25. Pesek, J.; Matyska, M.T. A comparison of two separation modes: HILIC and aqueous normal phase chromatography. LCGC N. Am. 2007, 25, 480-490.

26. Horvath, C.; Melander, W.; Molnar, I. Solvophobic interactions in liquid chromatography with non-polar stationary phases. J. Chromatogr. A 1976, 125, 129-156. [CrossRef]

27. Hanai, T. Definition of HILIC system and quantitative analysis of retention mechanisms. Cur. Chromatogr. 2018, 5, 43-52. [CrossRef]

28. Hanai, T. Introduction of in silico chromatography. J. Chromatogr. Sep. Tech. 2016, 7, 1-8. [CrossRef]

29. Hanai, T. Quantitative explanation of retention mechanisms of hydrophobic and hydrophilic interaction liquid chromatography-Inductive effect of alkyl-chain. Separations 2017, 4, 33. [CrossRef]

30. Hanai, T. Hydrophilic interaction liquid chromatography for LC-MS. Mass Spectrom. Purif. Tech. 2017, 4, 123. [CrossRef]

31. Hanai, T. Simple model bonded-phases to design a homogeneous support for in silico chromatography. Int. J. Anal. Tech. 2018, 4, 1-16. [CrossRef]

32. Hanai, T. Quantitative in silico analysis of the specificity of graphitized (graphitic) carbons. Adv. Chromatogr. 2011, 49, 257-290. [PubMed]

33. Hanai, T.; Hatano, H.; Nimura, N.; Kinoshita, T. Computer-aided analysis of molecular recognition in chromatography. Analyst 1993, 118, 1371-1374. [CrossRef] 
34. Hanai, T.; Koizumi, K.; Kinoshita, T.; Arora, R.; Ahmed, F. Prediction of pKa values of phenolic and nitrogen-containing compounds by computational chemical analysis compared to those measured by liquid chromatography. J. Chromatogr. A 1997, 762, 55-61. [CrossRef]

35. Hanai, T. Chromatography in silico, quantitative analysis of retention mechanisms of benzoic acid derivatives. J. Chromatogr. A 2005, 1087, 45-51. [CrossRef]

36. Hanai, T. Molecular modeling for quantitative analysis of molecular interaction. Lett. Drug Des. Discov. 2005, 2, 232-238. [CrossRef]

37. Hanai, T.; Homma, H. Chromatography in silico: Retention of acidic drugs on a guanidino ion-exchanger. J. Liq. Chromatogr. Relat. Technol. 2007, 30, 1723-1731. [CrossRef]

38. Hanai, T.; Masuda, Y.; Homma, H. Chromatography in silico; Retention of basic compounds on a carboxyl ion exchanger. J. Liq. Chromatogr. Relat. Technol. 2005, 28, 3087-3097. [CrossRef]

39. Hanai, T. Simulation chromatography of phenolic compounds using a computational chemical method. J. Chromatogr. A 2003, 1027, 279-287. [CrossRef]

40. Hanai, T.; Mizutani, C.; Homma, H. Computational chemical simulation of chromatographic retention of phenolic compounds. J. Liq. Chromatogr. Relat. Technol. 2003, 26, 2031-2039. [CrossRef]

41. Hanai, T. In silico modeling study on molecular interactions in reversed-phase liquid chromatography. J. Chromatogr. Sci. 2015, 53, 1084-1091. [CrossRef] [PubMed]

42. Hanai, T.; Miyazaki, R.; Koseki, A.; Kinoshita, T. Computational chemical analysis of the retention of acidic drugs on a pentyl-bonded silica gel in reversed-phase liquid chromatography. J. Chromatogr. Sci. 2004, 42, 354-360. [CrossRef]

43. Hanai, T. Chromatography in silico for basic drugs. J. Liq. Chromatogr. Relat. Technol. 2005, 28, $2163-2177$. [CrossRef]

44. Hanai, T. Quantitative in silico analysis of retention in normal-phase liquid chromatography. J. Liq. Chromatogr. Relat. Technol. 2010, 33, 297-304. [CrossRef]

45. Hanai, T. In silico chromatography: Modeling a new support for alkyl-bonded phases and a solvent phase. J. Anal. Bioanal. Sep. Tech. 2017, 2, 111-117. [CrossRef]

46. Islam, M.R.; Lu, Z.; Li, X.; Sarker, A.K.; Hu, L.; Choi, P.; Li, X.; Hakobyan, N.; Serpe, M.J. Responsive polymers for analytical applications: A review. Anal. Chim. Acta 2013, 789, 17-32. [CrossRef] [PubMed]

47. Lenca, N.; Poole, C.F. Liquid chromatography with room temperature ionic liquids. J. Plan. Chromatogr. Modern TLC 2017, 30, 97-105. [CrossRef]

48. Clark, K.D.; Emaus, M.; Varona, M.N.; Bowers, A.N.; Anderson, J.L. Ionic liquids; solvents and solbents in sample preparation. J. Sep. Sci. 2018, 41, 209-235. [CrossRef] [PubMed]

49. Das, R.N.; Roy, K. Advances in QSPR/QSTR models of ionic liquids for the design of greener solvents of the future. Mol. Div. 2013, 17, 151-196. [CrossRef] [PubMed]

50. Tobiszewski, M.; Namiesnik, J. Greener organic solvents in analytical chemistry. Cur. Opinion Green Subst. Chem. 2017, 5, 1-4. [CrossRef]

51. Soares, B.; Passos, H.; Freire, C.S.R.; Coutinho, J.A.P.; Silvestre, A.J.D.; Freire, M.G. Ionic liquids in chromatographic techniques: Toward additional improvements in the separation of natural compounds. Green Chem. 2016, 18, 4582-4604. [CrossRef] [PubMed]

52. Berton, P.; Lana, N.B.; Rios, J.M.; Garcia-Reyes, J.F.; Altamirano, J.C. State of the art of environmentally friendly sample preparation approaches for determination of PBDEs and metabolites in environmental and biological samples: A critical review. Anal. Chim. Acta 2016, 905, 24-41. [CrossRef] [PubMed]

53. Yabre, M.; Ferey, L.; Some, I.T.; Gaudin, K. Greening reversed-phase liquid chromatography methods using alternative solvents for pharmaceutical analysis. Molecules 2018, 23, 1065. [CrossRef]

54. Shi, X.; Qiao, L.; Xu, G. Recent development of ionic liquid stationary phases for liquid chromatography. J. Chromatogr. A 2015, 1420, 1-15. [CrossRef]

55. Vidal, L.; Riekkola, M.-L.; Canals, A. Ionic liquid-modified materials for solid-phase extraction and separation. Anal. Chim. Acta 2012, 715, 19-41. [CrossRef]

56. Marcinkowski, L.; Pereira, F.; Kloskowski, A.; Namiesnik, J. Opportunities and shortcomings of ionic liquids in single-drop microextraction. TrAC 2015, 72, 153-168. [CrossRef]

57. Spietelun, A.; Marcinkowski, L.; De la Guardia, M.; Mamiesnik, J. Green aspects, developments and perspectives of liquid phases microextraction techniques. Talanta 2014, 119, 34-45. [CrossRef] 
58. Martinis, E.M.; Grijalba, A.C.; Perez, M.B.; Llaver, M.; Wuilloud, R.G. Synergistic analytical preconcentration with ionic liquid-nanomaterial hybrids. TrAC 2017, 97, 333-344. [CrossRef]

59. Nawata, J.; Dawidziuk, B.; Dziedzic, D.; Gordon, D.; Popiel, S. Applictions of ionic liquids in analytical chemistry with a particular emphasis on their use in solid-phase microextraction. $\operatorname{Tr} A C \mathbf{2 0 1 8}, 105,18-36$.

60. Hawkins, C.A.; Momen, M.A.; Dietz, M.L. Application of ionic liquids in the preparation of extraction chromatographic materials for metal ion separations: Progress and prospects. Sep. Sci. Technol. 2018, 53, 1820-1833. [CrossRef]

61. Pang, L.; Liu, J.-F. Development of a solid-phase microextraction fiber by chemical binding of polymeric ionic liquid on a silica coated stainless steel wire. J. Chromatogr. A 2012, 1230, 8-14. [CrossRef]

62. Vidal, L.; Parshintsev, J.; Hartonen, K.; Canals, A.; Riekkola, M.-L. Ionic liquid-functionalized silica for selective solid-phase extraction of organic acids, amines and aldehydes. J. Chromatogr. A 2012, 1226, 2-10. [CrossRef] [PubMed]

63. Qiu, H.; Jiang, Q.; Wei, Z.; Wang, X.; Liu, X.; Jiang, S. Preparation and evaluation of a silica-based 1-alkyl-3-(propyl-3-sulfonate) imidazolium zwitter ionic stationary phase for high-performance liquid chromatography. J. Chromatogr. A 2007, 1163, 63-69. [CrossRef]

64. Hu, W.; Haddad, P.R.; Hasebe, K.; Tanaka, K. Electrostatic ion chromatography using hydroxide solution as mobile phase with suppressed conductivity detection. Anal. Commun. 1999, 36, 309-312. [CrossRef]

65. Rukhadze, M.; Lominadze, N.; Akhalkatsi, L.; Gvaramia, M. Study of chromatographic characteristics of inorganic analytes in biopartitioning miceller cdhromatography with ion-pair additives. Biomed. Chromatogr. 2010, 24, 1338-1341. [CrossRef]

66. Mysling, S.; Palmisano, G.; Hojrup, P.; Thaysen-Andersen, M. Utilizing ion-pairing hydrophilic interaction chromatography solid phase extraction for efficient glycopeptide enrichment in glycoproteomics. Anal. Chem. 2010, 82, 5598-5609. [CrossRef]

67. Garcia-Alvarez-Coque, M.C.; Ruiz-Angel, M.J.; Berthod, A.; Carda-Broch, S. On the use of ionic liquids as mobile phase additives in high-performance liquid chromatography. Anal. Chim. Acta 2015, 883, 1-21. [CrossRef] [PubMed]

68. Kartsova, L.A.; Bessonova, E.A.; Kolobova, E.A. Ionic liquids as modifiers of chromatographic and electrophoretic systems. J. Anal. Chem. 2016, 71, 141-152. [CrossRef]

69. Buszewska-Forajta, M.; Markuszewski, M.L.; Kaliszan, R. Free silanols and ionic liquids as heir suppressors in liquid chromatography. J. Chromatogr. A 2018, 1559, 17-43. [CrossRef]

70. Qiu, H.; Mallik, A.K.; Takafuji, M.; Liu, X.; Jiang, S.; Ihara, H. Enhancement of molecular shape selectivity by in situ anion-exchange in poly(octadecylimidazolium)silica column. J. Chromatogr. A 2012, 1232, 116-122. [CrossRef] [PubMed]

71. Pino, V.; Afonso, A.M. Surface-bonded ionic liquid stationary phases in high-performance liquid chromatography. Anal. Chim. Acta 2012, 714, 20-37. [CrossRef] [PubMed]

72. Bi, W.; Zhou, J.; Row, K.-H. Preparation and application of ionic liquid-modified stationary phases in high performance liquid chromatography. Sep. Sci. Technol. 2012, 47, 360-369. [CrossRef]

73. Qiao, L.; Dou, A.; Shi, X.; Li, H.; Shan, Y.; Lu, X.; Xu, G. Development and evaluation of new imidazolium-based zwitterionic stationary phases for hydrophilic interaction chromatography. J. Chromatogr. A 2013, 137-145. [CrossRef]

74. Zhang, M.; Liang, X.; Jiang, S.; Qiu, H. Preparation and applications of surface-confined ionic-liquid stationary phases for liquid chromatography. TrAC 2014, 53, 60-72. [CrossRef]

75. Cardoso, P.A.; Cesar, I.C. Chiral method development strategies for HPLC using macrocyclic glysopeptide-based stationary phases. Chromatographia 2018, 81, 841-850. [CrossRef]

76. Zhang, M.; Mallik, A.K.; Takafuji, M.; Ihara, H.; Qiu, H. Versatile ligands for high-performance liquid chromatography: An overview of ionic liquid-functionalized stationary phases. Anal. Chim. Acta 2015, 887, 1-16. [CrossRef]

77. Hawkins, C.A.; Rud, A.; Guthrie, M.L.; Dietz, M.L. Rapid quantification of imidazolium-based ionic liquids by hydrophilic interaction liquid chromatography: Methodology and an investigation of the retention mechanisms. J. Chromatogr. A 2015, 1400, 54-64. [CrossRef] [PubMed]

78. Liu, S.; Xu, H.; Yu, J.; Li, D.; Li, M.; Qiao, X.; Qin, X.; Yan, H. Novel imidazolium-embedded $\mathrm{N}, \mathrm{N}$-dimethylaminopropyl-functionalized silico-based stationary phase for hydrophilic/reversed-phase mixed-mode chromatography. Anal. Bioanal. Chem. 2015, 407, 8989-8997. [CrossRef] [PubMed] 
79. Qiao, L.; Shi, X.; Xu, G. Recent advances in development and characterization of stationary phases for hydrophilic interaction chromatography. TrAC 2016, 81, 23-33. [CrossRef]

80. Hadley, M.R.; Harrison, M.W.; Hutt, A.J. Use of chiral zwitterionic surfactants for enantiomeric resolutions by capillary electrophoresis. Electrophoresis 2003, 24, 2508-2513. [CrossRef] [PubMed]

81. Kapnissi-Christodoulou, C.P.; Stavrou, I.J.; Mavroudi, M.C. Chiral ionic liquids in chromatographic and electrophoretic separations. J. Chromatogr. A 2014, 2-10. [CrossRef] [PubMed]

82. Singh, A.; Chopra, H.K. Chiral ionic liquids: Design, synthesis and applications in asymmetric organocatalysis. Curr. Org. Syn. 2017, 14, 488-510. [CrossRef]

83. Hui, B.Y.; Raoov, M.; Zain, N.N.M.; Mohamad, S.; Osman, H. Combination of cyclodextrin and ionic liquid in analytical chemistry: Current and future perspectives. Crit. Rev. Anal. Chem. 2017, 47, 454-468. [CrossRef]

84. Masini, J.C.; Svec, F. Porous monoliths for on-line smple preparation: A review. Anal. Chim. Acta 2017, 964, 24-44. [CrossRef]

85. Shan, Y.; Qiao, L.; Shi, X.; Xu, G. Preparation and evaluation of a novel hybrid monolithic column based on pentafluorobenzyl imidazolium bormide ionic liquid. J. Chromatogr. A 2015, 1375, 101-109. [CrossRef]

86. Kamichatani, W.; Inoue, Y.; Saito, M.; Kobayashi, Y.; Yamamoto, A. Counter-ionic effect on the separation of water-soluble compounds applying hydrophilic stationary phase onded with a zwitter-ionic polymer. Anal. Sci. 2011, 27, 885-888. [CrossRef]

87. Olofsson, M.A.; Bylund, D. Liquid Chromatography with electrospray ionization and tandem mass cpectrometry applied in the quantitative analysis of chitin-derived glucosamine for a rapid estimation of fungal biomass in soil. Int. J. Anal. Chem. 2016, 2016, 9269367. [CrossRef] [PubMed]

88. Tang, B.; Bi, W.; Tian, M.; Row, K.H. Application of ionic liquid for extraction and separation of bioactive compounds from plants. J. Chromatogr. B 2012, 904, 1-21. [CrossRef] [PubMed]

89. Kailasa, S.K.; Rawat, K.A.; Wu, H.-F. Ionic liquids in bioanalysis. Bioanalysis 2015, 7, 2251-2264. [CrossRef] [PubMed]

90. Dash, R.P.; Srinivas, N.R.; Rais, R. A review of bioanalytical quantitative methods for selected sphingosine 1-phosphate receptor modulators. Biomed. Chromatogr. 2018, 32, e4109. [CrossRef] [PubMed]

91. Abbas, M.A.; Rasheed, A.S. Retention characteristic of ranitidine hydrochloride on new polymer-based in zwitter ion chromatography-hydrophilic interaction chromatography stationary phases. J. Chem. Soc. Pakistan 2018, 40, 89-94.

92. Meyer, A.; Hoffler, S.; Fischer, K. Anion-exchange chromatography-electrospray ionization mass spectrometry method development for the environmental analysis of aliphatic polyhydroxy carboxylic acids. J. Chromatogr. A 2007, 1170, 62-72. [CrossRef] [PubMed]

93. Huang, Y.; Yao, S.; Song, H. Aplication of ionic liquids in liquid chromatography and electrodriven separation. J. Chromatogr. Sci. 2013, 51, 739-752. [CrossRef]

94. Farajzadeh, M.A.; Khoshmaram, L.; Sheykhizadeh, S. A review on application of microextraction techniques for analysis of chemical compounds and metal ions in foodstuffs. Anal. Bioanal. Chem. Res. 2014, 1, 1-19.

95. Sun, M.; Feng, J.; Chen, W.; Li, L.; Duan, H.; Luo, C. Improvement of the chromatographic separation performance of an imidazolium ionic liquid functionalized silica column by in situ anion-exchange with dodecyl sulfonate and dodecylbenzene sulfonate anions. J. Sep. Sci. 2014, 37, 1283-1288. [CrossRef] [PubMed]

96. Grzeskowiak, T.; Czarczynska-Goslinska, B.; Zgota-Grezeskowiak, A. Current approaches in sample preparation for trace analysis of selected endocrine-disrupting compounds: Focus on polychlorinated biphenyls, alkylphenols, and parabens. TrAC 2016, 75, 209-226. [CrossRef]

97. Mitkare, S.S.; Lakhane, K.G.; Kokulwar, P.U. Ionic liquids: Novel applications in drug delivery. Res. J. Pharm. Technol. 2013, 6, 1274-1278.

98. Zeng, Y.; Liu, G.; Ma, Y.; Chen, X.; Ito, Y. Organic-high ionic strength aqueous solvent systems for spriral counter-current chromatography: Graphic optimization of partition coefficient. J. Liq. Chromatogr. Rel. Technol. 2013, 36, 504-512.

99. Zeng, Y.; Liu, G.; Ma, Y.; Chen, X.; Ito, Y. Organic high ionic strength aqueous two phase solvent system series for separation of ultra-polar compounds spiral high-speed counter-current chromatography. J. Chromatogr. A 2011, 1218, 8715-8717. [CrossRef] [PubMed]

100. Kirkland, J.J. Modern Practice of Liquid Chromatography; Wiley: New York, NY, USA, 1971; p. 454. ISBN O-471-48878-X. 
101. Snyder, L.R.; Kirkland, J.J. Introduction to Modern Liquid Chromatography; John Wiley: New York, NY, USA, 1979; p. 863. ISBN O-471-03822-9.

102. Snyder, L.R. Principles of Adsorption Chromatography; Marcel Dekker: New York, NY, USA, 1968; p. 174.

103. Small, H.; Stevens, T.S.; Bauman, W.C. Novel ion-exchange chromatographic method using conductmetric detection. Anal. Chem. 1975, 47, 1801-1809. [CrossRef]

104. Kirkland, J.J.; Langlois, T.J. Process for preparing substrates with porous surface. U.S. Patent 2009/0297853 A1, 23 June 2009.

105. Wyndham, K.D.; Muriithi, B.W.; Morris, M.T.; Lawrence, N.L. Superficially porous materials comprising a substantially non porous core having narrow particle size distribution; Process for the preparation thereof; and use thereof for chromatographic separations. WO 2012/018598, 26 July 2010.

106. Blue, L.E.; Jorgenson, J.W. $1.1 \mu \mathrm{m}$ superficially porous particles for liquid chromatography. Part I: Synthesis and particle structure characterization. J. Chromatogr. A 2011, 1218, 7989-7995. [CrossRef] [PubMed]

107. Diamond Analytics. Available online: http:/ / diamond-analytics.com/app-notes/flare-small-molecules / (accessed on 1 January 2019).

108. Nakamura, T.; Mizutani, M.; Nozaki, H.; Suzuki, N.; Yano, K. Formation mechanism for mono-dispersed meso-porous silica spheres and its applications to the synthesis of core/shell particles. J. Phys. Chem. C 2007, 111, 1093-1100. [CrossRef]

109. Glennon, J.D.; Omamogho, J. A process for preparing silica micro particles. WO 2010/061367 A2, 26 November 2008.

110. Kaiser, C.; Unger, K.K. Porous monodispersed SiO2 particles. WO 97/007056, A1, 16 August 1995.

111. Coakley, J.M.; Hanrahan, J.P.; Hogan, J.J.; Spalding, T.R.; Tobin, J.M. Silica core-shell microparticles. WO 2012/110995 A1, 16 February 2011.

112. Omamogho, J.O.; Hanrahan, J.P.; Tobin, J.; Glennon, J.D. Porous shell of $1.7 \mu \mathrm{m}$ core-shell silica particles on chromatographic performance: Narrow bore columns. J. Chromatogr. A 2011, 1218, 1942-1953. [CrossRef]

113. Dong, H.; Brennan, J.D. One-pot synthesis of silica core-shell particles with double shells and different pore orientations from their nonporous counterparts. J. Mat. Chem. 2012, 22, 13197-13203. [CrossRef]

114. Ahmed, A.; Ritchie, H.; Myers, P.; Zhang, H. One-pot synthesis of spheres-on-sphere silica particles from a single precursor for fast HPLC with low back pressure. Adv. Mat. 2012, 24, 6042-6048. [CrossRef]

115. Ahmed, A.; Abdelmagid, W.; Ritchie, H.; Myers, P.; Zhang, H. Investigation on synthesis of spheres-on-sphere silica particles and their assessment for high performance liquid chromatography applications. J. Chromatogr. A 2012, 1270, 194-203. [CrossRef]

116. Min, Y.; Jiang, B.; Wu, C.; Xia, S.; Zhang, X.; Liang, Z.; Zhang, L.; Zhang, Y. $1.9 \mu$ m superficially porous packing material with radially oriented pores and tailored pore size for ultra-fast separation of small molecules and biomolecules. J. Chromatogr. A 2014, 1356, 148-156. [CrossRef] [PubMed]

117. Langsi, V.K.; Ashu-Arrah, B.A.; Glennon, J.D. Sub-2- $\mu \mathrm{m}$ seeded growth mesoporous thin shell particles for high-performance liquid chromatography: Synthesis, functionalization and characterization. J. Chromatogr. A 2015, 1402, 17-26. [CrossRef] [PubMed]

118. Qu, Q.; Min, Y.; Zhang, L.; Xu, Q.; Yin, Y. Silica microspheres with fibrous shells: Synthesis and application in HPLC. Anal. Chem. 2015, 87, 9631-9638. [CrossRef] [PubMed]

119. Wei, T.-C.; Mack, A.; Chen, W.; Liu, J.; Dittmann, M.; Wang, X.; Barber, W.E. Synthesis, characterization, and evaluation of a superficially porous particle with unique, elongated pore channels normal to the surface. J. Chromatogr. A 2016, 1440, 55-65. [CrossRef] [PubMed]

120. Enke, D.; Glaser, R.; Tallarek, U. Sol-gel and porous glass-based silica monoliths with hierarchiral pore structure for solid-liquid catalysis. Chemie-Ingenieur-Technik 2016, 88, 1561-1585. [CrossRef]

121. Wang, X.; Zhang, Y.; Luo, W.; Elzatahry, A.A.; Chen, X.; Alghamdi, A.; Abdullah, A.M.; Deng, Y.; Zhao, D. Synthesis of ordered miso-porous silica with tunable morphologies and pore sizes via a non-polar solvent-assisted Stober method. Chem. Mater. 2016, 28, 2356-2362. [CrossRef]

122. Wei, T.-C.; Chen, W.; Barber, W.E. Superficially porous metal oxide particles, methods for making them, and separation devices using them. US 8,685,283, B2, 29 August 2008.

123. Daneyko, A.; Höltzel, A.; Khirevich, S.; Tallarek, U. Influence of the particle size distribution on hydraulic permeability and eddy dispersion in bulk packings. Anal. Chem. 2011, 83, 3903-3910. [CrossRef]

124. Bruns, S.; Stoeckel, D.; Smarsly, B.M.; Tallarek, U. Influence of particle properties on the wall region in packed capillaries. J. Chromatogr. A 2012, 1268, 53-63. [CrossRef] 
125. Gritti, F.; Guiochon, G. Theoretical investigation of diffusion along columns packed with fully and superficially porous particles. J. Chromatogr. A 2011, 1218, 3476-3488. [CrossRef]

126. Gritti, F.; Guiochon, G. Diffusion models in chromatographic columns packed with fully and superficially porous particles. Chem. Eng. Sci. 2011, 66, 3773-3781. [CrossRef]

127. Fekete, S.; Fekete, J. The impact of extra-column band broadening on the chromatographic efficiency of $5 \mathrm{~cm}$ long narrow-bore very efficient columns. J. Chromatogr. A 2011, 1218, 5286-5291. [CrossRef] [PubMed]

128. Gritti, F.; Guiochon, G. Mass transfer kinetics, band broadening and column efficiency. J. Chromatogr. A 2012, 1221, 2-40. [CrossRef] [PubMed]

129. Gritti, F.; Guiochon, G. Measurement of the eddy dispersion term in chromatographic columns. II. Application to new prototypes of 2.3 and 3.2mm I.D. monolithic silica columns. J. Chromatogr. A 2012, 1227, 82-95. [CrossRef] [PubMed]

130. Gritti, F.; Shiner, S.; Fairchild, J.N.; Guiochon, G. Characterization and kinetic performance of $2.1 \times 100 \mathrm{~mm}$ production columns packed with new $1.6 \mu \mathrm{m}$ superficially porous particles. J. Sep. Sci. 2014, 37, 3418-3425. [CrossRef] [PubMed]

131. Gritti, F.; Shiner, S.J.; Fairchild, J.N.; Guiochon, G. Evaluation of the kinetic performance of new prototype $2.1 \mathrm{~mm} \times 100 \mathrm{~mm}$ narrow-bore columns packed with $1.6 \mu \mathrm{m}$ superficially porous particles. J. Chromatogr. A 2014, 1334, 30-43. [CrossRef] [PubMed]

132. Gritti, F.; Guiochon, G. The quantitative impact of the mesopore size on the mass transfer mechanism of the new $1.9 \mu \mathrm{m}$ fully porous Titan-C18 particles.1: Analysis of small molecules. J. Chromatogr. A 2015, 1384, 76-87. [CrossRef]

133. McGillicuddy, N.; Nesterenko, E.P.; Nesterenko, P.N.; Stack, E.M.; Omamogho, J.O.; Glennon, J.D.; Paull, B. A new $N$-hydroxyethyliminodiacetic acid modified core-shell silica phase for chelation ion chromatography of alkaline earth, transition and rare earth elements. J. Chromatogr. A 2013, 1321, 56-64. [CrossRef]

134. Mignot, M.; De Saint Jores, C.; Tchapla, A.; Boyer, F.; Cardinae, P.; Peulon-Agasse, V. New anthracenyl polar embedded stationary phases with enhanced aromatic selectivity, a combined experimental and theoretical study: Part 1-experimental study. J. Chromatogr. A 2017, 1512, 9-21. [CrossRef]

135. Patel, D.C.; Breitbach, Z.S.; Wahab, M.F.; Barhate, C.L.; Armstrong, D.W. Gone in seconds: Praxis, performance, and peculiarities of ultrafast chiral liquid chromatography with superficially porous particles. Anal. Chem. 2015, 87, 9137-9148. [CrossRef]

136. Spudeit, D.A.; Breitbach, Z.S.; Dolzan, M.D.; Micke, G.A.; Armstrong, D.W. Superficially porous particle based hydroxypropyl- $\beta$-cyclodextrin stationary phase for high-efficiency enantiomeric separations. Chirality 2015, 27, 788-794. [CrossRef]

137. Patel, D.C.; Breitbach, Z.S.; Yu, J.; Nguyen, K.A.; Armstrong, D.W. Quinine bonded to superficially porous particles for high-efficiency and ultrafast liquid and supercritical fluid chromatography. Anal. Chim. Acta 2017, 963, 164-174. [CrossRef] [PubMed]

138. Catani, M.; Felletti, S.; Ismail, O.H.; Gasparrini, F.; Pasti, L.; Marchetti, N.; De Luca, C.; Costa, V.; Cavazzini, A. New frontiers and cutting edge applications in ultra high performance liquid chromatography through latest generation superficially porous particles with particular emphasis to the field of chiral separations. Anal. Bioanal. Chem. 2018, 2457-2465. [CrossRef] [PubMed]

139. DeStefano, J.J.; Schuster, S.A.; Lawhorn, J.M.; Kirkland, J.J. Performance characteristics of new superficially porous particles. J. Chromatogr. A 1258, 1258, 76-83. [CrossRef] [PubMed]

140. Fekete, S.; Veuthey, J.-L.; Guillarme, D. New trends in reversed-phase liquid chromatographic separations of therapeutic peptides and proteins: Theory and applications. J. Pharm. Biom. Anal. 2012, 69, 9-27. [CrossRef] [PubMed]

141. Schuster, S.A.; Wagner, B.M.; Boyes, B.E.; Kirkland, J.J. Optimized superficially porous particles for protein separations. J. Chromatogr. A 2013, 1315, 118-126. [CrossRef] [PubMed]

142. Preti, R. Core-shell columns in high-performance liquid chromatography: Food analysis applications. Int. J. Anal. Chem. 2016, 2016, 3189724. [CrossRef]

(C) 2019 by the author. Licensee MDPI, Basel, Switzerland. This article is an open access article distributed under the terms and conditions of the Creative Commons Attribution (CC BY) license (http:/ / creativecommons.org/licenses/by/4.0/). 